\title{
Emission reduction potential of using ethanol-biodiesel-diesel fuel blend on a heavy-duty diesel engine
}

\author{
Xiaoyan Shi ${ }^{\mathrm{a}}$, Xiaobing Pang ${ }^{\mathrm{a}}$, Yujing Mu ${ }^{\mathrm{a}}$, Hong $\mathrm{He}^{\mathrm{a}, *}$, Shijin Shuai ${ }^{\mathrm{b}}$, \\ Jianxin Wang ${ }^{b}, \mathrm{Hu}$ Chen ${ }^{\mathrm{b}}$, Rulong $\mathrm{Li}^{\mathrm{b}}$ \\ ${ }^{a}$ State Key Laboratory of Environmental Chemistry and Ecotoxicology, Research Center for Eco-environmental of Sciences, \\ Chinese Academy of Sciences, Beijing 100085, China \\ ${ }^{\mathrm{b}}$ State Key Laboratory of Automotive Safety and Energy, Tsinghua University, Beijing 100084, China
}

Received 6 September 2005; received in revised form 25 November 2005; accepted 7 December 2005

\begin{abstract}
Oxygenated diesel fuel blends have a potential to reduce the emission of particulate matter (PM) and to be an alternative to diesel fuel. This paper describes the emission characteristics of a three compounds oxygenated diesel fuel blend (BEdiesel), on a Cummins-4B diesel engine. BE-diesel is a new form of oxygenated diesel fuel blends consisted of ethanol, methyl soyate and petroleum diesel fuel. The blend ratio used in this study was 5:20:75 (ethanol: methyl soyate: diesel fuel) by volume. The results from the operation of diesel engine with BE-diesel showed a significant reduction in PM emissions and $2 \%-14 \%$ increase of $\mathrm{NO}_{x}$ emissions. The change of $\mathrm{CO}$ emission was not conclusive and depended on operating conditions. Total hydrocarbon (THC) from BE-diesel was lower than that from diesel fuel under most tested conditions. Formaldehyde, acetaldehyde, propionaldehyde and acetone in the exhaust were measured, and the results indicated that use of BE-diesel led to a slight increase of acetaldehyde, propionaldehyde and acetone emissions. A small amount of ethanol was also detected in the exhaust from burning BE-diesel.
\end{abstract}

(C) 2006 Elsevier Ltd. All rights reserved.

Keywords: Diesel engine; Biodiesel; Ethanol; Alternative fuel; Emissions

\section{Introduction}

As public concern about environmental pollution and energy security increases, alternative diesel fuels, such as biodiesel, Fischer-Tropsch (F-T) diesel and ethanol-diesel fuel blends, are receiving more and more attention. Biodiesel and ethanol can be produced from feedstocks that are generally

\footnotetext{
*Corresponding author. Tel.: + 861062849123 ; fax: +861062923563 .

E-mail address: honghe@rcees.ac.cn (H. He).
}

considered to be renewable. Since the carbon in the biodiesel originated mostly from $\mathrm{CO}_{2}$ in the air, the full cycle $\mathrm{CO}_{2}$ emissions for biodiesel contribute much less to global warming than fossil fuels. Although biodiesel cannot entirely replace petroleum-based fuels, biofuels and diesel fuel blends can be used on existing engines to achieve both environmental and energy benefits.

The vegetable oil ester-based biodiesel has long been used as fuel for diesel engines. Many studies about the use of biodiesel fuels in diesel engines have been done and some of them have been reviewed 
(Graboski and McCormick, 1998; Graboski et al., 2003). Biodiesel has properties similar to those of traditional fossil diesel fuel such that it can be substituted for diesel fuel with little or no engine modification. Studies clearly indicate that the use of biodiesel may potentially reduce the dependence on petroleum diesel fuel and improve air quality. Substantial reduction in particulate emissions can be obtained through the addition of biodiesel to diesel fuel. B20 (a mixture of 20\% biodiesel and 80\% petroleum diesel) has become the most popular biodiesel fuel blend used and this blend level has been studied in different countries (Durbin and Norbeck, 2002; Durbin et al., 2002; Lee et al., 2004).

Ethanol is a low cost oxygenate with high oxygen content $(35 \%)$ that has been used in ethanol-diesel fuel blends. The use of ethanol in diesel fuel can yield significant reduction of particulate matter (PM) emissions for motor vehicles (Ahmed, 2001; Lü et al., 2004; He et al., 2003; Zhang et al., 2004). However, there are many technical barriers to the direct use of ethanol in diesel fuel due to the properties of ethanol, including low cetane number of ethanol and poor solubility of ethanol in diesel fuel in cold weather. In fact, diesel engines cannot operate normally on ethanol-diesel blend without special additives (McCormick and Parish, 2001; Gerdes and Suppes, 2001).

Biodiesel is known to act as an emulsifier for ethanol (McCormick et al., 2001). Blending biodiesel and ethanol into a conventional diesel fuel dramatically improved the solubility of ethanol in diesel fuel over a wide range of temperature.

Fernando and Hanna (2004) reported that the ethanol-biodiesel-diesel fuel blends are stable well below sub-zero temperature and have equal or superior fuel properties to regular diesel fuel. Makareviciene et al. (2005) characterized the solubility of biodiesel fuel components in fossil diesel-methanol-rapeseed oil methyl ester, fossil diesel-ethanol-rapeseed oil methyl ester and fossil diesel-ethanol-rapeseed oil ethyl ester systems. They also proved that addition of ester to ethanol and fossil diesel fuel mixture increases solubility of ethanol in diesel fuel. The low flashpoint of ethanol-diesel blend is a technical barrier to the application of this fuel blend. Studies show that the presence of emulsifiers has no effect on flashpoint (McCormick et al., 2001).

These studies suggested that blends of biodiesel, ethanol, and diesel fuel could improve some properties of biodiesel-diesel blends and ethanol-diesel blends. Their studies paved the way to formulate a new form of biofuel and diesel fuel blend. In regard of an alternative fuel, however, we must consider not only the technical practicability, but also its exhaust gas emissions and possible impacts on the environment and human health.

Our previous studies examined ethanol-biodiesel-diesel fuel blends on a four-cylinder commercial DI diesel engine (Sofim 8140.43C type) and the results were compared their regulated emissions with those from $20 \%$ biodiesel fuel blend (B20) and diesel fuel. The blend ratios of ethanol and biodiesel were selected to have the same viscosity as that of diesel fuel. We also proved that the ethanol-biodiesel-diesel fuel blends had better properties of water tolerance and stability than ethanol-diesel (Shi et al., 2005). One result of that study was the more reduction of PM with ethanol-biodiesel-diesel fuel blends compared to the biodiesel-diesel fuel blends, even if the blend ratios of additive to diesel fuel were the same. The PM reduction appeared to be related to the amount of oxygen content in the fuel blends (Shi et al., 2005). Based on that study, the blending of biodiesel, ethanol and diesel fuel is considered as a promising alternative fuel for diesel.

In order to get more detailed exhaust characteristic data on the ethanol-biodiesel-diesel fuel blends, our current study is to determine both regulated and some important unregulated exhaust emissions that are major concerns for oxygenated diesel fuel. The diesel engine used in this study was a four-cylinder Commins-4B diesel engine, which is different from the one used in our previous study. Regulated emissions of PM, nitrogen oxides $\left(\mathrm{NO}_{x}\right)$, carbon monoxide $(\mathrm{CO})$, total unburned hydrocarbon (THC), and carbon dioxide $\left(\mathrm{CO}_{2}\right)$ were investigated and they were compared with the emissions of diesel fuel. Unregulated emissions including formaldehyde, acetaldehyde and propionaldehyde, acetone and ethanol in the exhaust from burning BE-diesel were also measured and discussed.

\section{Experimental setup}

Commercial diesel fuel used in China was employed in this study as baseline diesel fuel and it was obtained locally. Provided by a local supplier, the biodiesel, methyl soy ester, was synthesized through a reaction between soybean oil and methanol. The ethanol used in this study was analysis-grade anhydrous ethanol (99.7\% purity). 
Table 1

Fuel properties

\begin{tabular}{|c|c|c|c|c|}
\hline Properties & Diesel & Methyl soyate & Ethanol & BE-diesel \\
\hline Boiling point, ${ }^{\circ} \mathrm{C}$ & $180-330$ & 330 & 78 & - \\
\hline Cloud point, ${ }^{\circ} \mathrm{C}$ & -5 & 0 & - & -5 \\
\hline Density, $\mathrm{g} \mathrm{ml}^{-1}$ at $20^{\circ} \mathrm{C}$ & 0.84 & 0.88 & 0.789 & 0.845 \\
\hline Oxygenate, wt. $\%$ & $\mathrm{n} / \mathrm{a}$ & 11 & 35 & 3.9 \\
\hline Carbonate, wt. $\%$ & 87 & 77 & 52 & 83 \\
\hline Hydrogen, wt. \% & 13 & 11.8 & 13 & 12.8 \\
\hline Viscosity, cS at $40^{\circ} \mathrm{C}$ & 3.11 & 4.75 & 1.2 & 3.04 \\
\hline Cetane number & 46 & 55 & 6 & 45 \\
\hline Flash point, ${ }^{\circ} \mathrm{C}$ & 78 & $>110$ & 13.5 & - \\
\hline Gross heat content, $\mathrm{MJ} \mathrm{kg}^{-1}$ & 42.5 & 38.0 & 27.0 & 40.9 \\
\hline
\end{tabular}

Based on the results of our previous experiments (Shi et al., 2005), the ratios of fuel blend were 5:20:75 (ethanol: biodiesel: diesel) by volume, which was denoted by BE-diesel in the current literature. The properties of the test fuels are reported in Table 1.

All experiments were performed with Cummins4B diesel engine (4-cylinder, $3.92 \mathrm{~L}$ displacement, 17.5: 1 compression ratio). Table 2 shows the engine specifications. Prior to executing each experiment, the engine was fully warmed. A Zöllner electric eddy dynamometer was coupled to the engine to measure the engine power.

An exhaust gas analyzer (AVL CEB-11 type) was employed to measure emissions of $\mathrm{NO}_{x}, \mathrm{THC}, \mathrm{CO}$ and $\mathrm{CO}_{2}$ on line in raw exhaust. The relative standard deviations of the analyzer, are $<1 \%$ for $\mathrm{NO}_{x},<5 \%$ for $\mathrm{CO},<3 \%$ for THC and $<0.2 \%$ for $\mathrm{CO}_{2}$. At each operating condition, the sampling duration was $10 \mathrm{~min}$. Total PM was measured by an AVL PM sampler with exhaust dilution and a sampling system. PM was collected on a PTFE coated glass filter (AVL, USA). The filter was conditioned at $25^{\circ} \mathrm{C}$ and $50 \%$ humidity, and it was weighed before and after the sampling procedure.

The measurement of carbonyl compounds including formaldehyde, acetaldehyde, propionaldehyde and acetone was mainly based on the EPA Method TO-11A (US EPA, 1999). All samples were collected by DNPH-coated Sep-Pak Silica Gel cartridges (Waters, USA). The sampled cartridges were eluted slowly with 5.0-mL ACN, and then the eluted solutions were determined by a HPLC-UV system (HP1050, USA). Each sample was analyzed three times and the relative standard deviations were less than $5 \%$. The sample is regulated by a mass flow controller driven by set points issued in response to
Table 2

Engine specifications

\begin{tabular}{ll}
\hline Cylinder number & 4 \\
Bore $(\mathrm{mm}) \times$ stroke, $\mathrm{mm}$ & $102 \times 120$ \\
Displacement, $L$ & 3.92 \\
Compression ratio & $17.5: 1$ \\
Rated power $(\mathrm{kW}) / \mathrm{speed}\left(\mathrm{r} \mathrm{min}^{-1}\right)$ & $76 / 2800$ \\
Maximum torque $(\mathrm{Nm}) / \mathrm{speed}\left(\mathrm{r} \mathrm{min}^{-1}\right)$ & $245 / 1600$ \\
\hline
\end{tabular}

the exhaust tunnel temperature. Exhaust gas samples were also taken in a gas sample bag from in raw gas to determine the ethanol in the exhaust by a gas chromatography. Each gas sample in the bag was analyzed three times and the relative standard deviations were kept less than $10 \%$. The detection limit is in the ppb-range.

Two types of experimental units were carried out in this study: constant load/varying speed tests (engine performance at various speeds with full load) and constant speed/varying load tests (engine performance at steady speed, $1800 \mathrm{rpm}$, with varying loads).

\section{Results and discussion}

\subsection{Regulated emissions}

Oxygenated diesel fuel blends are known to reduce total PM emissions. However, the mechanisms for the reduction in PM by oxygenate addition have not been fully explained. Soot formation mainly takes place in the fuel-rich zone at high temperature and pressures, specifically within the core region of each fuel spray. It is commonly assumed that oxygenates blended with diesel fuel effectively deliver oxygen to the pyrolysis zone of 
the burning diesel spray resulting in reduced PM generation (McCormick et al., 2001; Wang et al., 2000). The oxygen weight content in the BE-diesel is about $3.5 \%$ while that in the diesel fuel is near to zero. Therefore, BE-diesel was expected to reduce PM emissions. Fig. 1 shows that, depending on test modes, the BE-diesel significantly reduced PM emission by $21-39 \%$.

The effect of oxygenated fuel blends on $\mathrm{NO}_{x}$ emissions is complex and is not conclusive. Either cetane number, fuel density or aromatic fuel composition can influence on $\mathrm{NO}_{x}$ emissions. Many studies indicate that oxygenate fuel blends could cause slight increases in $\mathrm{NO}_{x}$ emissions (Ali et al., 1995; Graboski et al., 2003; McCormick et al., 2001; Wang et al., 2000). Our results also demonstrated a few percent increase in $\mathrm{NO}_{x}$ emissions at most operation conditions when the diesel engine was fueled with BE-diesel. As shown in Fig. 2, the $\mathrm{NO}_{x}$ emissions from BE-diesel increased by $11.4 \%$ at the constant speed/varying load tests and increased about $5.6 \%$ at the constant load/varying speed tests compared with that from diesel fuel.



Fig. 1. Comparison of PM emissions for BE-diesel (BE) and diesel fuel (D).
Selective catalytic reduction is an attractive technology to lower diesel exhaust $\mathrm{NO}_{x}$ emissions, and considerable researches have been done in this area. Previous studies from our laboratory showed that $\mathrm{Ag} / \mathrm{Al}_{2} \mathrm{O}_{3}$-ethanol $\mathrm{NO}_{x}$ catalytic converter satisfied the $\mathrm{NO}_{x}$ emission requirements of the Euro III standard using the European Economic Community's 13-mode test cycle ( $\mathrm{He}$ and $\mathrm{Yu}, 2005$; Shuai et al., 2005). Combination of BE-diesel and $\mathrm{Ag} / \mathrm{Al}_{2} \mathrm{O}_{3}$-ethanol system on diesel engine may provide a possibility to reduce PM emissions and $\mathrm{NO}_{x}$ emissions simultaneously.

The variations of $\mathrm{CO}$ emissions with respect to fuels, loads and engine speeds are shown in Fig. 3 . $\mathrm{CO}$ emissions appeared to be test mode specific. At constant speed, $\mathrm{CO}$ emissions from BE-diesel were greater than those from diesel fuel at most tested modes. In full load tests, $\mathrm{CO}$ emissions decreased at high speeds and increased at low speeds. Although biofuel and diesel fuel blends were reported to reduce $\mathrm{CO}$ emissions (Durbin et al., 2002; Wang et al., 2000), the results of $\mathrm{CO}$ emissions from ethanol-diesel are various. Some studies reported reduction of $\mathrm{CO}$ emissions by using ethanol-diesel (Zhang et al., 2004) while opposite results were also observed (He et al., 2003; Lü et al., 2004).

Fig. 4 shows that $\mathrm{CO}_{2}$ emissions from BE-diesel were higher than that from diesel fuel at some operating conditions while the opposite results were also found. In average, BE-diesel increased $\mathrm{CO}_{2}$ emissions by an average of $3.5 \%$.

Ethanol and diesel fuel blends were reported to increase THC emissions, but biodiesel blends were found to produce lower THC emissions than diesel fuel. (Caro et al., 2001; He et al., 2003; Lü et al., 2004; Durbin et al., 2002; Wang et al., 2000). Fig. 5 shows that THC was decreased moderately when the diesel engine was fueled with BE-diesel. The
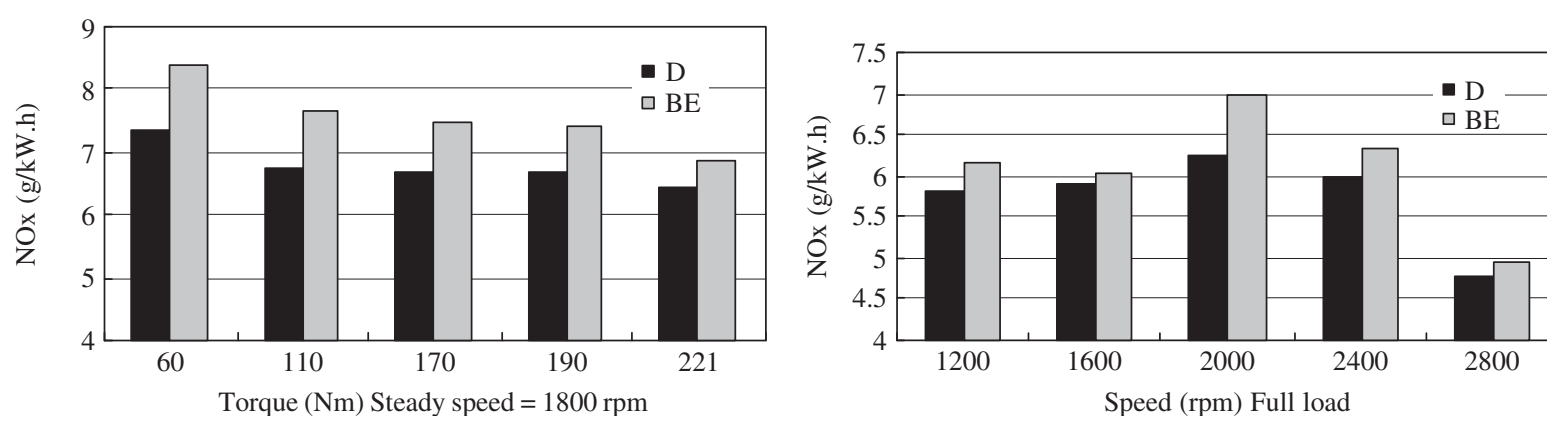

Fig. 2. Comparison of $\mathrm{NO}_{x}$ emissions for BE-diesel (BE) and diesel fuel (D). 

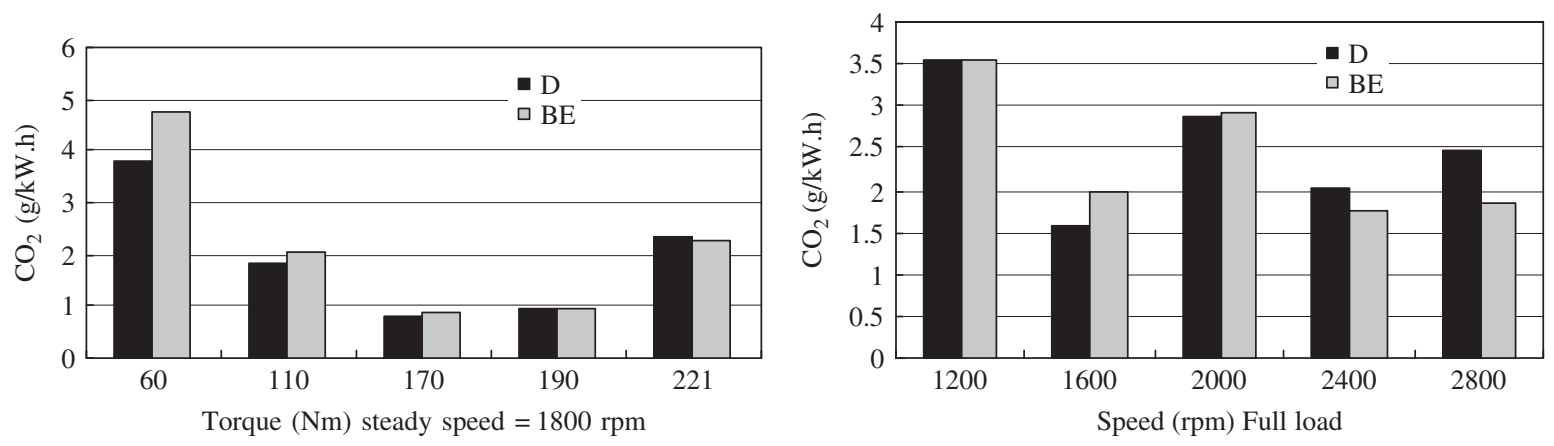

Fig. 3. Comparison of $\mathrm{CO}$ emissions for BE-diesel (BE) and diesel fuel (D).
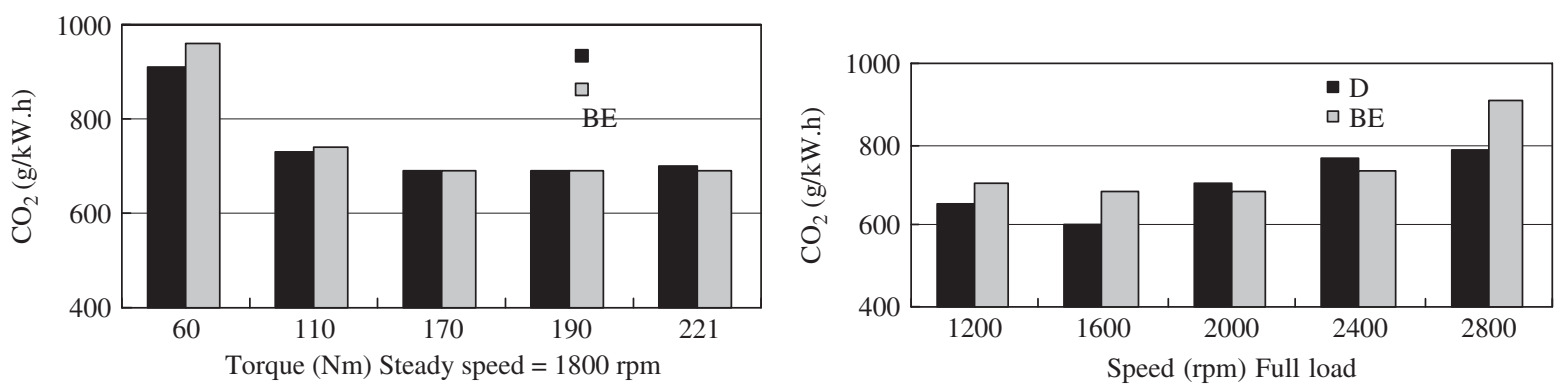

Fig. 4. Comparison of $\mathrm{CO}_{2}$ for BE-diesel (BE) and diesel fuel (D).
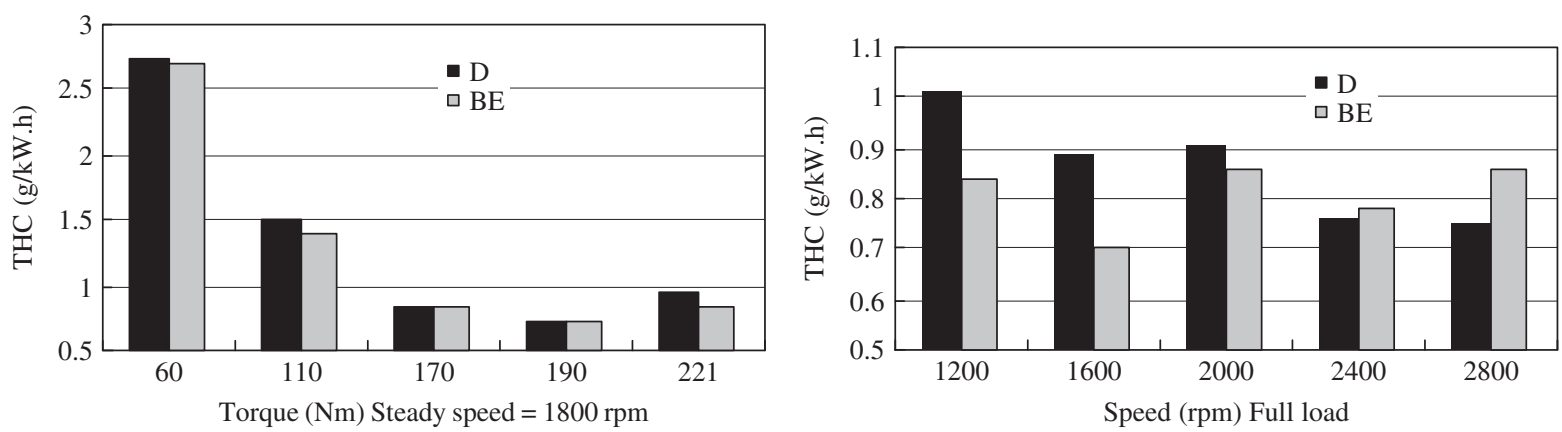

Fig. 5. Comparison of THC emissions for BE-diesel (BE) and diesel fuel (D).

reduction rates were about $4.2 \%$, for the constant load/varying speed tests and about $5.3 \%$ for the constant load/varying speed tests relative to diesel fuel.

\subsection{Unregulated emissions}

In order to meet the requirements of increasing stringent environmental regulations, it is important to understand the effects of BE-diesel on emissions of some specific compounds that may have mutagenic activity.
Carbonyl compounds are one of the components in the exhaust emissions. Because of their important role as obligatory intermediates in atmospheric photo oxidation, carbonyl compounds in vehicular exhaust have received attention as toxic air contaminants. Formaldehyde, acetaldehyde, propionaldehyde and acetone are the four largest emission factors of carbonyl emissions from vehicles (Grosjean et al., 2001). Fig. 6 shows that BE-diesel generally decreased formaldehyde emissions by about $30 \%$ despite some variations at different loads. At full load, compared to formaldehyde 



Fig. 6. Comparison of formaldehyde emissions for BE-diesel (BE) and diesel fuel (D).
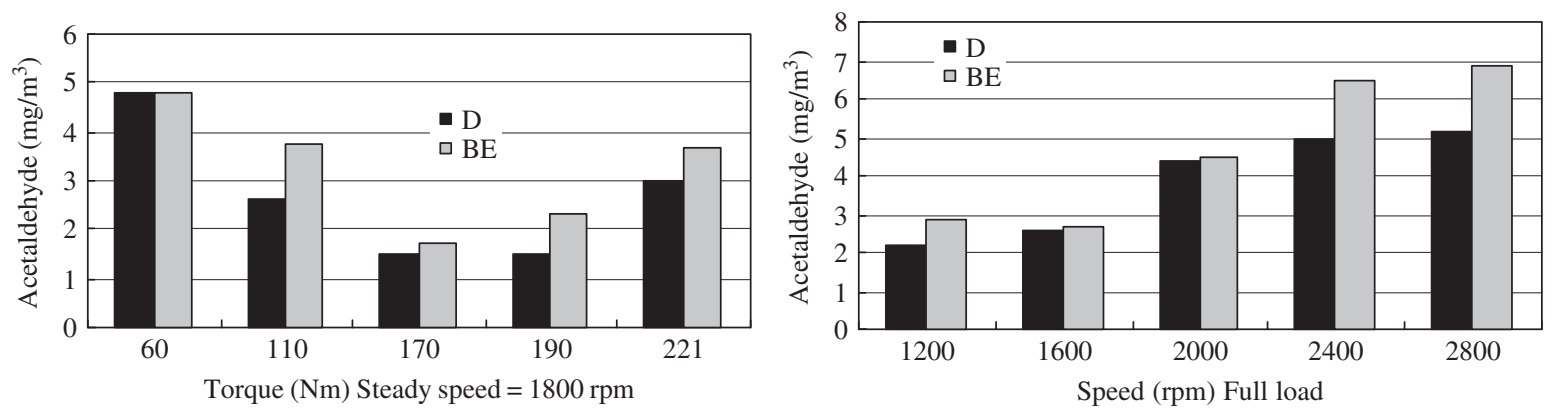

Fig. 7. Comparison of acetaldehyde emissions for BE-diesel (BE) and diesel fuel (D).

emissions for diesel fuel, formaldehyde emissions for BE-diesel was higher when engine speed was below $1600 \mathrm{rpm}$, but they were lower at speeds above $1600 \mathrm{rpm}$. The average formaldehyde emissions in the exhaust decreased $20 \%$ for BE-diesel relative to diesel fuel.

The use of ethanol-diesel was found to increase emissions of acetaldehyde and unburned ethanol due to the existence of ethanol in fuel (He et al., 2003). In this study, BE-diesel produced more acetaldehyde emissions than diesel fuel at all the test modes (Fig. 7). At full load, acetaldehyde emissions increased with the increase of engine speed. At steady speed, this emission was lowest at a medium load. The average concentration of acetaldehyde in the exhaust from BE-diesel was about $20 \%$ higher than that from diesel fuel. A small amount of ethanol was found in the exhaust using the fuel blend (Fig. 8), suggesting that the 5\% ethanol in BE-diesel would not be fully combusted. Consistent with other studies (He et al., 2003; Zhang et al., 2004), our study found no ethanol was observed in the exhaust from diesel fuel in the present study.
The amount of propionaldehyde in the exhaust from both BE-diesel and diesel was lower than $2.5 \mathrm{mg} \mathrm{m}^{-3}$ at the test modes (Fig. 9). Propionaldehyde emissions from BE-diesel were increased in a range of $6 \%$ to $49 \%$ compared with those from diesel fuel.

Formaldehyde and acetaldehyde are two major aldehydes species in the exhaust from vehicles (Grosjean et al., 2001). Comparing Figs. 6 and 7, one can find that the use of BE-diesel decreased the emissions of formaldehyde and increased the emissions of acetaldehyde. According to the difference in relative abundance of the four major components was observed between diesel fuel and BE-diesel fuel, the formaldehyde/acetaldehyde emission factors ratio was ca. 1.2 for diesel fuel and ca. 0.56 for BE-diesel. Overall, a slight increase of total aldehyde emissions was observed with BE-diesel compared with diesel fuel.

Using BE-diesel increased acetone emissions at all the selected test modes (Fig. 10). The largest acetone emissions with BE-diesel were twice of those with diesel fuel. As a conclusion, BE-diesel increased acetone emissions as compared with diesel fuel. 

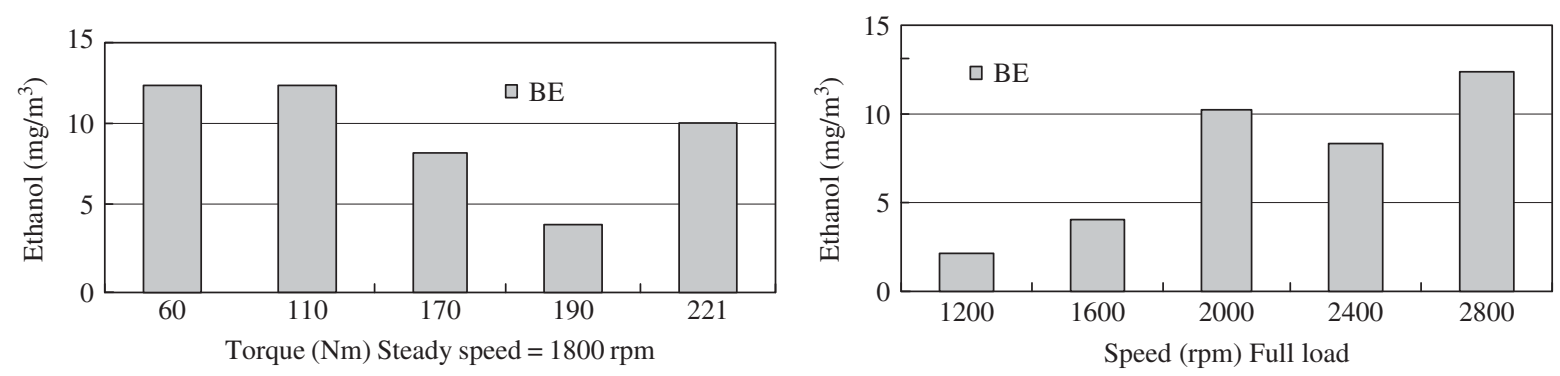

Fig. 8. Ethanol emissions from BE-diesel (BE).
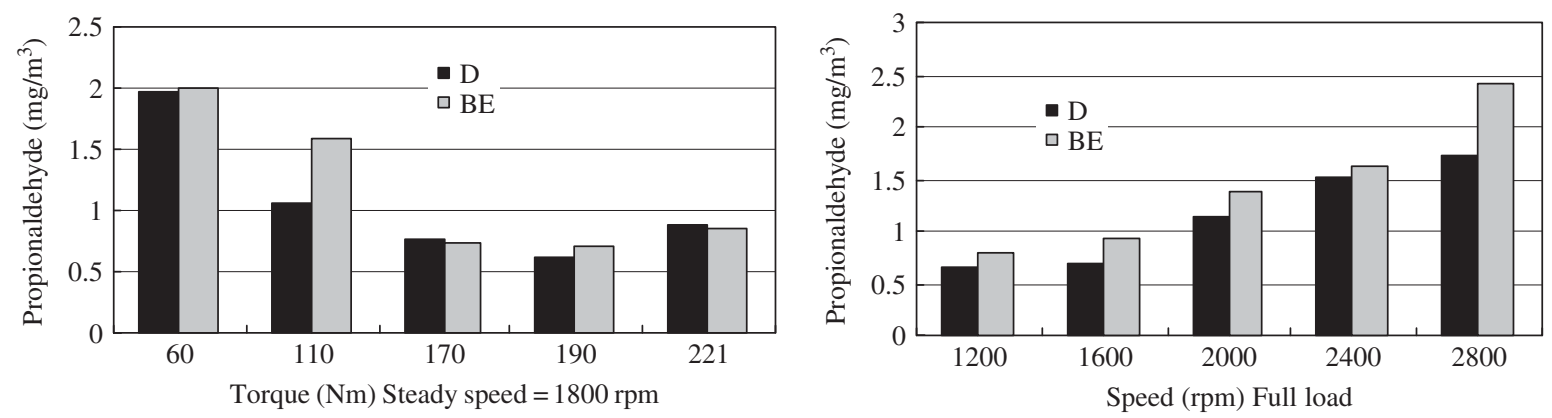

Fig. 9. Comparison of propionaldehyde emissions for BE-diesel (BE) and diesel fuel (D).
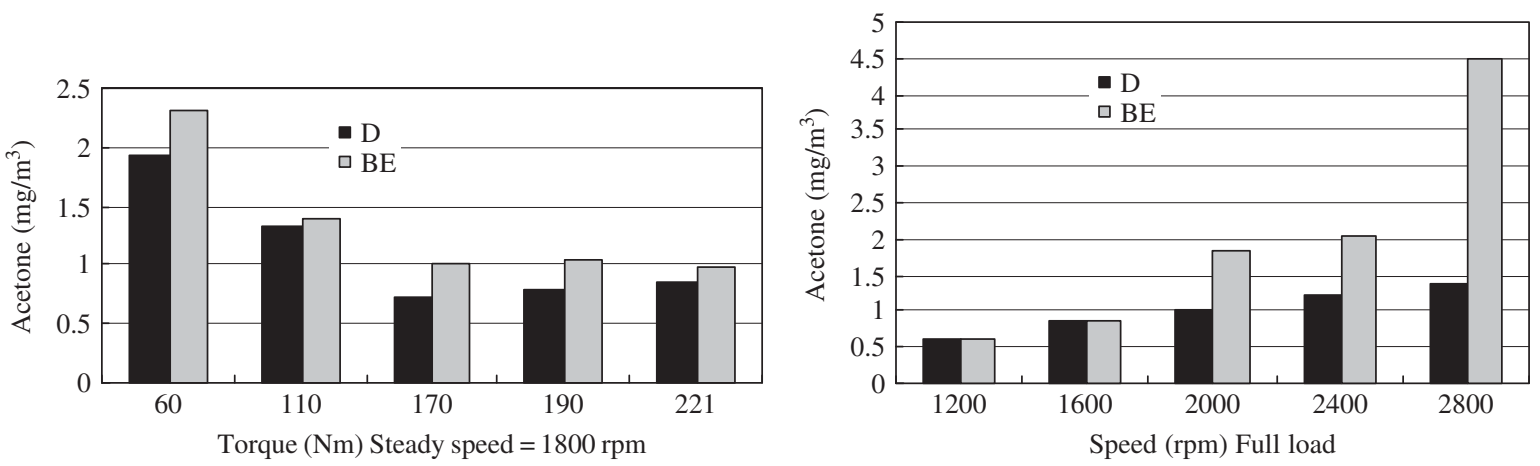

Fig. 10. Comparison of acetone emissions for BE-diesel (BE) and diesel fuel (D).

The emissions of acetaldehyde, ethanol, propionaldehyde and acetone exhibit similar trends in depending on the test modes. Quite different from the trends in formaldehyde emissions, these emissions increased with the increase of engine speed.

\section{Conclusion}

The emission characteristics of a Cummins-4B diesel engine using biodiesel-ethanol-diesel fuel blends were investigated and compared with those using diesel fuel. The application of BE-diesel can reduced PM emissions by $30 \%$ in average. However, BE-diesel did lead to a slight increase of $\mathrm{NO}_{x}$ emissions in a range of $5.6-11.4 \%$ at tested conditions. The impact of BE-diesel on CO emissions varies with engine operating conditions and was not conclusive. A general reduction in THC was obtained under the operation conditions. Combined results on formaldehyde, acetaldehyde, propionaldehyde and acetone suggest that the use of BEdiesel leads to a slight increase of acetone and total aldehyde. A small amount $\left(2-12 \mathrm{mg} \mathrm{m}^{-3}\right)$ of ethanol was observed in the exhaust using BE-diesel which 
was not in the exhaust from diesel fuel. In summary, BE-diesel can be directly used on a diesel engine for lower PM and THC emissions.

\section{Acknowledgements}

This work was financially supported by the Innovation Program of the Chinese Academy of Sciences (KZCX3-SW-430).

\section{References}

Ahmed, I., 2001. Oxygenated diesel: emissions and performance characteristics of ethanol-diesel blends in CI engines. SAE Technology paper 2001-01-2475.

Ali, Y., Hanna, M.A., Leviticus, L.I., 1995. Emissions and power characteristics of diesel engines on methyl soyate and diesel fuel blends. Bioresource Technology 52, 185-195.

Caro, P.S., Mouloungui, Z., Vaitilingom, G., Berge, J.C., 2001. Interest of combining an additive with diesel-ethanol blends for use in diesel engine. Fuel 80, 565-574.

Durbin, T.D., Norbeck, J.M., 2002. Effects of biodiesel blends and arco EC-diesel on emissions from light heavy-duty diesel vehicles. Environmental Science and Technology 36, 1686-1691.

Durbin, T.D., Collins, J.R., Norbeck, J.M., Smith, M.R., 2002. Effects of biodiesel, biodiesel blends and a synthetic diesel on emissions from light heavy-duty diesel vehicles. Environmental Science and Technology 34, 349-355.

Fernando, S., Hanna, M., 2004. Development of a novel biofuel blend using ethanol- biodiesel-diesel miscroemulsions: EBdiesel. Energy and Fuels 18, 1695-1703.

Gerdes, KR., Suppes, GJ., 2001. Miscibility of ethanol in diesel fuels. Industrial and Engineering Chemistry Research 40, 949-956.

Graboski, M.S., McCormick, R.L., 1998. Combustion of fat and vegetable oil derived fuels in diesel engines. Progress in Energy Combustion Science 24, 125-164.

Graboski, M.S., McCormick, R.L., Alleman, T.L., Herring, A.M., 2003. The effect of biodiesel composition on engine emissions from a DDC Series 60 diesel engine. Final report to NREL/SR-510-31461.
Grosjean, D., Grosjean, E., Gertler, A.W., 2001. On-road emissions of carbonyls from light-duty and heavyduty vehicles. Environmental Science and Technology 35, $45-53$.

He, H., Yu, Y., 2005. Selective catalytic reduction of $\mathrm{NO}_{x}$ over $\mathrm{Ag} / \mathrm{Al}_{2} \mathrm{O}_{3}$ catalyst: from reaction mechanism to diesel engine test. Catalysis Today 100, 37-47.

He, B.Q., Shuai, S.J., Wang, J.X., He, H., 2003. The effect of ethanol blended diesel fuels on emissions from a diesel engine. Atmospheric Environment 37, 4965-4971.

Lee, S.W., Herage, T., Yong, B., 2004. Emission reduction potential from the combustion of soy methyl ester fuel blended with petroleum distillate fuel. Fuel 83, 1607-1613.

Lü, X.C., Yang, J.G., Zhang, W.G., Huang, Z., 2004. Effect of cetane number improver on heat rate and emissions of high speed diesel engine fueled with ethanol-diesel blend fuel. Fuel 83, 2013-2020.

Makareviciene, V., Sendzikiene, E., Janulis, P., 2005. Solubility of multi-component biodiesel fuel systems. Bioresource Technology 96, 611-616.

McCormick, RL., Parish, R., 2001. Technical barriers to the use of ethanol in diesel fuel. Milestone report to NREL/MP-54032674.

McCormick, R.L., Michael, S., Graboski, Teresa, L., Alleman, Andrew, M., Herring, 2001. Impact of biodiesel source material and chemical structure on emissions of criteria pollutants from a heavy-duty engine. Environmental Science and Technology 35, 1742-1747.

Shi, X., Yu, Y., He, H., Shuai, S., Wang, J., Li, R., 2005. Emission characteristics using methyl soyate-ethanol-diesel fuel blends on a diesel engine. Fuel 84, 1543-1549.

Shuai, SJ., Wang, JX., Li, RL., Sun, J., Xing, L., He, H., Shi, XY., 2005. Performance evaluation and application of diesel $\mathrm{NO}_{x}$-SCR catalyst by ethanol reductant. SAE 2005-01-1089.

US. Environment Protection Agency (US EPA), 1999. Compendium method to-11A. Determination of formaldehyde in ambient air using adsorbent cartridge followed by high performance liquid chromatography (HPLC).

Wang, WG., Lyons, DW., Clark, NN., Gautam, M., 2000. Emissions from nine heavy trucks fueled by diesel and biodiesel blend without engine modification. Environmental Science and Technology 34, 933-939.

Zhang, RD., He, H., Shi, XY., He, BQ., Wang, JX., 2004. Preparation and emission characteristics of ethanol-diesel fuel blends. Journal of Environmental Science 16, 793-796. 